\title{
INTERNET OF THINGS (IOT) IN TOURISM AND HOSPITALITY: OPPORTUNITIES AND CHALLENGES
}

\author{
Tomislav Car \\ Ljubica Pilepić Stifanich \\ Mislav Šimunić
}

https://doi.org/10.20867/tosee.05.42

\begin{abstract}
Purpose - An increasing number of tourist destinations and hotels are using new technology and solutions to promote their products and services. IoT represents a great opportunity for tourism and hospitality to increase customer satisfaction while simultaneously reducing operational costs. The purpose of this paper is to define what IoT actually is and to find out how it can be of benefit to people in tourism and hospitality. The aims of this paper are to provide an insight into IoT and explore how IoT solutions provide opportunities for tourism and hospitality to better serve customers, increase the efficiency of operations and provide differentiated services.

Methodology - Based on an extensive literature review, this study explores the development of IoT and its application in tourism and hospitality. This paper attempts to show the core components of IoT through a case-study analysis of well-established IoT technology. It offers a viewpoint on the current state of development and the future developments that are expected.

Findings - The research finds that technology (such as IoT, for example) will continue to impact guest service and customer relationship management in tourism and hospitality. The findings of this study suggest that the adoption of IoT technologies widely redesigns and improves the performance of all the main business processes in hospitality and can also be very useful in the tourism sector. Furthermore, the findings give new insight into the role of IoT, especially with regard to guest satisfaction enhancement and cost reduction.

Contribution - The paper provides an overview of IoT functionalities as well as insight into IoT application examples in a tourism and hospitality context. Moreover, the paper examines the practical implications about the role and use of IoT in tourism and hospitality and puts forward future guidelines for hotel (destination) managers, which should enable them to keep up with global tourism trends and put them on an equal footing with other participants in the online tourism and travel market. This paper contributes to the understanding of IoT and highlights the importance of new technology and solutions in tourism and hospitality that bring numerous benefits, starting with cost reduction, improved functionality, greater productivity and increased guest satisfaction. Also, this study provides meaningful new dimensions of important IoT-based features and services and can serve as a basis for further research in this area.

Keywords Internet of Things, Smart Tourism, Hospitality, Information and Communication Technology (ICT)
\end{abstract}

\section{INTRODUCTION}

The Internet of Things (IoT) represents a very important factor in the tourism and hotel industry, enabling new ways of doing business. Although numerous industries can potentially benefit from the Internet of Things, the travel industry is already leading the way when it comes to IoT investment. The Internet of Things - an ever-growing network of connected devices which communicate with a central server as well as with each other 
ToSEE - Tourism in Southern and Eastern Europe, Vol. 5, pp. 163-175, 2019

T. Car, Lj. Pilepić Stifanich, M. Šimunić: INTERNET OF THINGS (IOT) IN TOURISM AND ...

- is becoming more than just connectivity. According to Moreau (as cited in Dlodlo et al., 2016), IoT is considered a major research and innovation stream leading to numerous opportunities for new services by interconnecting physical and virtual worlds with huge amounts of electronic devices distributed in houses, vehicles, streets, buildings and many other public environments.

Table 1: IoT Units Installed Base by Category (Millions of Units)

\begin{tabular}{l|c|c|c|c}
\hline Category & $\mathbf{2 0 1 6}$ & $\mathbf{2 0 1 7}$ & $\mathbf{2 0 1 8}$ & $\mathbf{2 0 2 0}$ \\
\hline Consumer & $3,963.0$ & $5,244.3$ & $7,036.3$ & $12,863.0$ \\
\hline Business: Cross-Industry & $1,102.1$ & $1,501.0$ & $2,132.6$ & $4,381.4$ \\
\hline Business: Vertical-Specific & $1,316.6$ & $1,635.4$ & $2,027.7$ & $3,171.0$ \\
\hline Grand Total & $\mathbf{6 , 3 8 1 . 8}$ & $\mathbf{8 , 3 8 0 . 6}$ & $\mathbf{1 1 , 1 9 6 . 6}$ & $\mathbf{2 0 , 4 1 5 . 4}$
\end{tabular}

Source: Gartner (January 2017)

The statistic shows the installed base of the Internet of Things (IoT) by category between 2016 and 2020. According to Gartner, an estimated 12.86 billion units will be in use in the consumer segment by 2020. The consumer segment is the largest user of connected things with 7.04 billion units in 2018, which represents $63 \%$ of the overall number of applications in use (see Table 1).

As technology is becoming cheaper, more powerful as well as easier to use, much of the innovation has shifted towards enabling these smart devices and systems to communicate with each other. Some travel and hospitality brands already have some IoT functionality in their back-end operations and are experimenting with ways to put the new technology to work for customers (emarketer, 2016). There is no doubt that the adoption of IoT creates new challenges and opportunities and will affect the way we do business today.

\section{DEFINITION AND CONCEPT OF IOT}

Before we can begin to see the importance and opportunities of IoT, it is necessary to define and explain the concept of IoT. Table 2 shows various definitions of the IoT concept.

The term 'Internet of Things' was first used by Kevin Ashton in 1999. IoT is a network that can connect with anything anytime and anyplace by technologies of RFID (Radio Frequency IDentification), WSN (Wireless Sensor Network) and 3G/4G/5G mobile communication, according to an agreed protocol, in order to identify, locate, track, monitor and manage smart objects (Mingjun et al. 2012). 
ToSEE - Tourism in Southern and Eastern Europe, Vol. 5, pp. 163-175, 2019

T. Car, Lj. Pilepić Stifanich, M. Šimunić: INTERNET OF THINGS (IOT) IN TOURISM AND ...

Table 2: Various definitions of IoT

Definition of IoT

Author/s (year)

"a dynamic global network infrastructure with self-configuring capabilities based on standard and interoperable communication protocols where physical and virtual 'Things' have identities, physical attributes, and virtual personalities and use intelligent interfaces, and are seamlessly integrated into the information network"

"IoT is a system of interrelated computing devices, mechanical and digital machines, objects, animals or people that are provided with unique identifiers (UIDs) and the ability to transfer data over a network without requiring human-to-human or human-to-computer interaction."

"Internet of Things can be realized in three paradigms - internetoriented (middleware), things oriented (sensors) and semanticoriented (knowledge)."

Kranenburg (2008)

"A dynamic global network infrastructure with self-configuring capabilities based on standard and interoperable communication protocols where physical and virtual "things" have identities, physical attributes, and virtual personalities and use intelligent interfaces, and are seamlessly integrated into the information network."

"Interconnection of sensing and actuating devices providing the ability to share information across platforms through a unified framework, developing a common operating picture for enabling innovative

Gubbi et al. (2013) applications.'"

"The Internet of Things (IoT) is the network of physical objects that contain embedded technology to communicate and sense or interact with their internal states or the external environment."

Gartner (n.d.)

"A global infrastructure for the information society enabling advanced services by interconnecting (physical and virtual) things based on existing and evolving interoperable information and communication technologies."

"The Internet of Things (IoT) is defined as a paradigm in which objects equipped with sensors, actuators, and processors communicate with each other to serve a meaningful purpose."

Techtarget (n.d.)

Atzori et al. (2010)

IERC (n.d.)

ITU (2015)

Source: author's research

Figure 1 shows that with the Internet of Things, anything will able to communicate to the Internet at any time from any place to provide any service by any network to anyone. This concept will create new types of applications, which can involve smart vehicles and the smart home, to provide many services such as notifications, security, energy saving, automation, communication, computers and entertainment (Saranya and Nitha 2015; Sapandeep and Ikvinderpal 2016). 
ToSEE - Tourism in Southern and Eastern Europe, Vol. 5, pp. 163-175, 2019

T. Car, Lj. Pilepić Stifanich, M. Šimunić: INTERNET OF THINGS (IOT) IN TOURISM AND ...

Figure 1: Concept of IoT

Anytime

Anyone

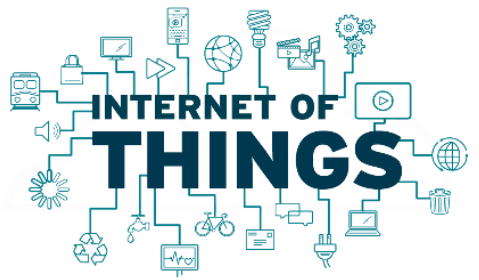

Anything

Any place

Any service

Any network

Source: Made by the author, after Zeinab and Elmustafa (2017)

Also, there are three main system-level characteristics of the Internet of Things (Miorandi et al. 2012):

(1) Anything communicates: smart things have the ability to wirelessly communicate among themselves, and form ad hoc networks of interconnected objects.

(2) Anything is identified: smart things are identified with a digital name: relationships among things can be specified in the digital domain whenever physical interconnection cannot be established.

(3) Anything interacts: smart things can interact with the local environment through sensing and actuation capabilities whenever present.

The main idea behind IoT is communication interfaces (e.g. near range low-power BLE - Bluetooth Low Energy, Wi-Fi or LTE - Long-Term Evolution) integrated in devices that are not communication user interfaces (Pustišek et al. 2014). However, from the user perspective, IoT scopes can be divided into personal (i.e. body range), ambient (room, house, hotel, museum, fitness facility) or environmental (city, destination).

The Internet of Things offers new opportunities to connect physical and digital worlds, and enables more direct and active interaction between tourists, hotels, tourism products and destinations. 
ToSEE - Tourism in Southern and Eastern Europe, Vol. 5, pp. 163-175, 2019

T. Car, Lj. Pilepić Stifanich, M. Šimunić: INTERNET OF THINGS (IOT) IN TOURISM AND ...

\section{THE INTERNET OF THINGS AND (SMART) TOURISM}

Given Gartner's prediction that there will be 26 billion IoT-connected devices by 2020 (Tossell 2015), all major tourism and hospitality companies have become aware of the importance of technology and the huge opportunities it provides for modern businesses. Smart tourism is a new form of tourism through the application of IoT, cloud computing, Big Data, Artificial Intelligence and other modern technologies in tourism experience, industrial development and administrative supervision (Wu 2017). Although often seen as a slower adopter of technology, the tourism industry is nevertheless continuously on the lookout for the latest innovations, such as IoT, which can enable further automation, more personalisation and a greater customer experience. It can also streamline day-today tasks that go into running a hotel or travel company (Revfine n.d.).

\section{Table 3: Ideas of smart tourism}

\section{Smart Tourism Ideas}

Use of sensors, cameras and smart phones

Use of Big Data to analyse information

Collaboration of web and mobile services

Use of cloud services and the Internet of Things (IoT)

Use of touch screens for easy interaction

Better assistance to tourists through mobile tours and apps

Source: Kaur and Kaur (2016)

Table 3 shows the different technologies that interact to provide smart tourism services such as web and mobile services, cloud computing, the Internet of Things (IoT) and Big Data analysis. IoT has enormous potential, especially as a tool which can provide new, and improve existing, solutions in the process of creating tourism products and services. By taking advantage of IoT technology, the tourism industry can achieve increased operational efficiency and provide more-personalized guest experiences.

Tourism is one of the sectors in which the rise of IoT applications is expected to greatly boost development. Some examples of IoT application in (smart) tourism are the following (Mimos Berhad 2014):

- Geo-location technologies that track whereabouts and information that enrich travel experiences - from route planning to accommodation arrangement and journey planning - are in good demand from trendy gadget makers. Tourists want the comfort and security of knowing that if they get into any trouble at any point of their journey, they are able to reach out to someone who can help them. Ubiquitous smart devices help travellers to record time, speed/pace, distance, location, elevation and allow instant communication with similar peers en route or who have checked into the same location. Using IoT, the mining of travel experience data will enable travel agents or tour operators to co-create tourism spot packages and create attractions and experiences that better suit the incoming visitors to enhance loyalty, engage consumers and enlist visitors. 
ToSEE - Tourism in Southern and Eastern Europe, Vol. 5, pp. 163-175, 2019

T. Car, Lj. Pilepić Stifanich, M. Šimunić: INTERNET OF THINGS (IOT) IN TOURISM AND ...

- Medical (wellness) tourism - “using IoT technologies, patients' health conditions will be monitored remotely and continuously as they enjoy a vacation while recuperating after a medical procedure. The vacation phase of post treatment will include follow-up for medical procedures via teleconsultation and support the continuity of care. Data collected on such tourists can boost industry competitiveness by generating and providing reliable and valid statistical reports on quality, safety and health outcomes, in addition to enabling healthcare providers to adopt best practices, processes and cost management effectiveness, and generate new market segments that involve more than just travel for travel insurance".

- Ecotourism or tourism activities based on nature - leveraging ubiquitous devices using IoT, tourism destinations can be quantified through direct measurement and social network interactions that increase the attractiveness of a particular destination. The industry can then employ the services of communications/ environmental design experts to provide 'services' such as e-demonstrator to offer unique cultural experience and activities, and e-ranger/e-tour guide for personalised travel guide services to enrich travel experience and ensure tourists' safety and security throughout the journey.

- Retail tourism services - the interaction between tourists' mobile devices and digital signages serves as a tool to dynamise, promote and sell, in addition to generating loyalty. Using IoT, these services enable tourism service providers ranging from hotels, ground transportation retailers to amusement parks - to understand their customers well and respond to customer needs by offering customers location-based services.

- Virtual concierge - travellers who take long vacations that span various destinations can engage a virtual concierge service, which stores, washes and repacks a traveller's wardrobe between trips, collects the traveller's suitcase from their hotel and delivers it to their next destination, minus the challenges of wrangling bags through cumbersome security lines. The virtual concierge will help customise the traveller's itineraries while the smart luggage tag tracks the baggage from gate to gate and provides automatic weather forecasts from one destination to another.

- At the airport - In the case of multiple entry to or exit from a country, communication terminals at the airport can be linked using IoT to process, analyse and allow or deny entry or exit to multiple individuals simultaneously. It helps prevent escapees due to human error and automates information sharing for decision making between customs and immigration terminals. For travellers/tourists, this means a smoother and faster verification process at the lanes, which results in fewer cases of missed flights, and shorter transit periods at the airport. In addition, at airports, IoT offers an opportunity to help travellers navigate sprawling terminals and receive targeted messages from retailers (Skift 2016). According to Sterling (2016), nearly $90 \%$ of airports deploy IoT-proximity sensors (also known as beacons)

There are many good examples of using IoT in tourism and some of them are shown here. Tourism and traveling is one of the leading industries to embrace technical innovations, IoT being one of them. This technology is forming a new reality - costefficient, eco-friendly and customer-centred - a bit at a time. Many companies are investing in IoT solutions, and this tendency seems to be increasing (Skelia 2018). 
ToSEE - Tourism in Southern and Eastern Europe, Vol. 5, pp. 163-175, 2019

T. Car, Lj. Pilepić Stifanich, M. Šimunić: INTERNET OF THINGS (IOT) IN TOURISM AND ... Figure 2: Size of the IoT market worldwide, from 2016 to 2020 (in billion U.S.
dollars)

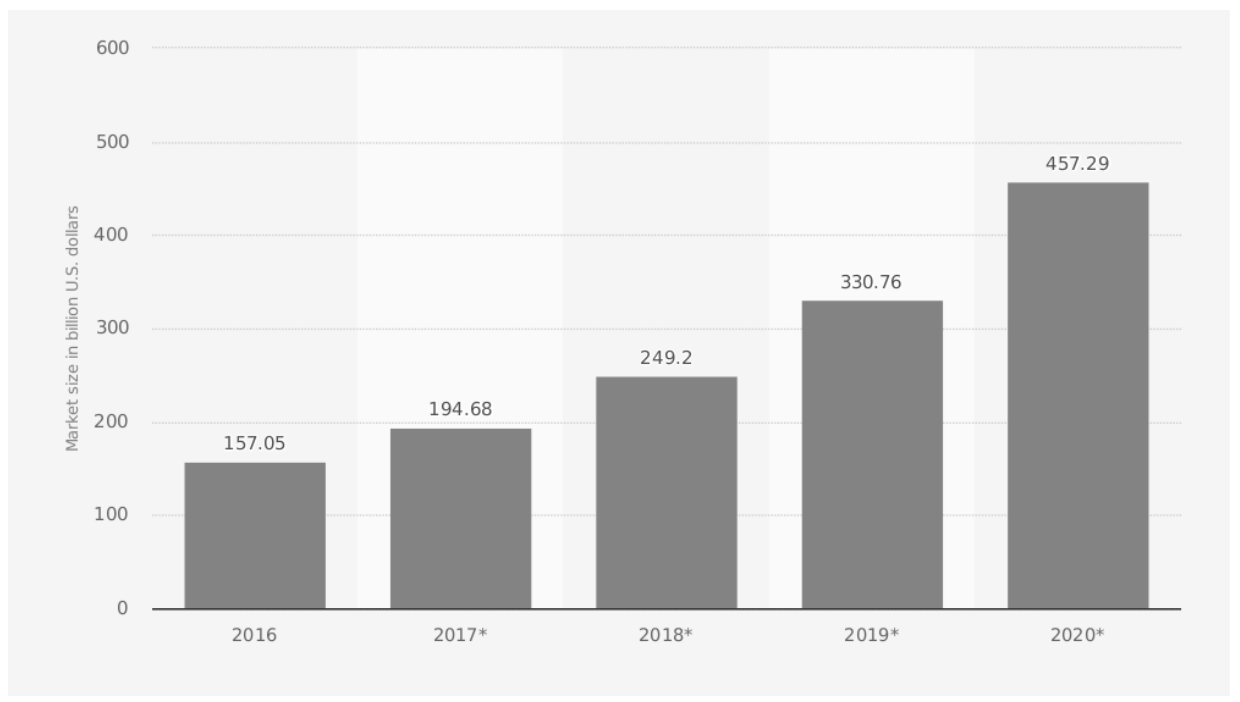

Source: Growth Enabler Statista (2019)

The figure shows the IoT market size worldwide, from 2016 to 2020. In 2020, the IoT market is forecast to reach 457.29 billion U.S. dollars. These numbers concerning the Internet of Things will help managers and others in tourism to understand the potential that IoT technology holds.

\section{IOT APPLICATION IN THE HOSPITALITY INDUSTRY}

IoT is used in many different areas to improve efficiency and provide a better customer experience. Homes are increasingly turning into smart homes and beginning to give way to smart hotels, bringing hoteliers an opportunity to better serve guests, offer value-added services, and run the facility on the back end with far greater efficiency than was ever before possible.

Innovations in smart devices and IoT are driving the reform of technology used in the hospitality service platform (Kansakar et al. 2017). The hotel industry can use IoT to provide integrated services such as application-driven devices and automated triggers like automated door locks, set-top-boxes, thermostats, telephones, light switches, voicebased interaction, electric blinds and other devices that are connected on a common network to enable the services that guests want. These kinds of facilities will make the guest experience more personalized and speedier, and the hotelier, more efficient. Also, hotels will be able to deliver more value to their guests at lower costs. Table 4 illustrates several solutions/examples of IoT in the hospitality industry. 
ToSEE - Tourism in Southern and Eastern Europe, Vol. 5, pp. 163-175, 2019

T. Car, Lj. Pilepić Stifanich, M. Šimunić: INTERNET OF THINGS (IOT) IN TOURISM AND ...

Table 4: Several solutions of IoT in the hospitality industry

$\begin{array}{ll}\text { Solution } & \text { Application / Example } \\ & \text { Hilton and Marriott have experimented with slightly different takes on the } \\ \text { 'connected room' concept, where users are able to control many of the } \\ \text { room's features from their mobile phone, or from a provided tablet. In } \\ \text { addition, IoT platforms could over time memorize a guest's specific } \\ \text { comfort preferences, such as temperature, lights, TV channels \& shades, } \\ \text { and automatically set up the room for their next stay. Hotels can } \\ \text { hotel rooms } & \text { automatically send electronic key cards to guests' smartphones, allowing } \\ & \text { them to check-in without anyone's assistance. }\end{array}$

Amazon Alexa enables the guest to use voice-control on different smart voice-based home devices. It's basically a guest's personal butler who never gets tired interaction of fulfilling their needs. Alexa can be configured by hospitality providers to allow guests to control and adjust in-room devices such as lights, thermostats, blinds and TVs.

Fast check-in: Starwood and Hilton, for example, already offer an option of checking in via a mobile gadget instead of spending time at the front desk. Control device: all the functions performed by quite a few remote controls, key cards and switches are now available at the click of a button on a mobile device.

integration with mobile

Wireless medical sensor technology further expands the scope of data collection by providing detailed data about organs and systems within the body. For example, service providers can filter out high carbohydrate and sugary meal options for diabetic guests, high cholesterol meal options for patients with heart disease, etc.

sensors

IoT will change the way hotels manage their inventories. IoT

inventory management implemented systems will keep record of the inventory and manage the changes in them automatically.

\begin{tabular}{ll}
\hline $\begin{array}{l}\text { Focation-based } \\
\text { information }\end{array}$ & $\begin{array}{l}\text { when guests are close by or advertising gym services when they are near } \\
\text { the gym. It may also mean sending up-to-date information about local } \\
\text { transport links, or nearby attractions... }\end{array}$
\end{tabular}

Flic - a wireless button

For example, when someone calls reception to ask for more towels or coffee. With Flic, guests could notify housekeepers about it with a press of a button. Ordering services and sending automated messages has never been this easy.

building automation and monitoring

For example, in-room monitoring systems can be used to detect whether a room is occupied or unoccupied so as to schedule housekeeping services.

Valpas autonomous bed bug prevention

"Valpas has developed an autonomous bed bug prevention system that allows guests to stay carefree from bed bug anxiety at exciting hotels around the world. By replacing their existing bed legs with Valpas' smart legs, hotels can monitor the rooms in real-time and receive notifications of eliminated bed bugs caught inside the legs." 
ToSEE - Tourism in Southern and Eastern Europe, Vol. 5, pp. 163-175, 2019

T. Car, Lj. Pilepić Stifanich, M. Šimunić: INTERNET OF THINGS (IOT) IN TOURISM AND ...

\begin{tabular}{|c|c|}
\hline Solution & Application / Example \\
\hline automation & $\begin{array}{l}\text { IoT automates the business functions of travel and hotel businesses. For } \\
\text { example, hotels can track supply chains more efficiently through sensors } \\
\text { in shipments, enabling them to get ready for any future contingency and } \\
\text { avoid service disruptions to guests. }\end{array}$ \\
\hline $\begin{array}{l}\text { augmented } \\
\text { reality and } \\
\text { beacon } \\
\text { technology }\end{array}$ & $\begin{array}{l}\text { For example, this technology can be used to provide guests with services } \\
\text { such as digitally guided tours, previews of in-room environment (e.g., } \\
\text { decor, facilities and amenities, etc.), immediate translation services for } \\
\text { signs and other written materials, interactive restaurant menus with dish } \\
\text { previews, critic reviews, food allergy information, etc. }\end{array}$ \\
\hline maint & $\begin{array}{l}\text { By installing sensors, hotels can track the condition of all electronic } \\
\text { devices and schedule the work of personnel according to whether the } \\
\text { guest is in or out of the room. In addition, predictive maintenance will } \\
\text { take hoteliers one-step further; it will use sensors to recognize the } \\
\text { problems and alert before the issue becomes hazardous. }\end{array}$ \\
\hline energy saving & $\begin{array}{l}\text { While IoT can enable personalisation, it can also offer businesses } \\
\text { financial benefits through automated or smart energy saving. }\end{array}$ \\
\hline \multicolumn{2}{|c|}{$\begin{array}{l}\text { Source: Author's research, after Ray (2016), Kansakar (2018), Nidhi (2018), Revfine (n.d.), Ansari (2018) } \\
\text { Jaakkola (2018), Devotex (n.d.) }\end{array}$} \\
\hline \multicolumn{2}{|c|}{$\begin{array}{l}\text { IoT is already being applied in the hospitality industry and the future potential it has for } \\
\text { hotel owners makes it important for them to understand and use IoT. In addition, it can } \\
\text { help to automate processes, improve the guest experience and help hospitality companies } \\
\text { to save money on energy costs and maintenance. To come to closer terms with their } \\
\text { present and future guests, hotels need to continuously monitor trends on the ever more } \\
\text { discerning and burgeoning tourism market and adapt to the development of new } \\
\text { technologies to remain competitive. }\end{array}$} \\
\hline
\end{tabular}

\section{IOT CHALLENGES}

IoT devices with limited functionality have been around for at least a decade. What has changed recently is the ubiquity of connectivity options (Wi-Fi, 4G/5G, Bluetooth, etc.), cloud services and analytics, which are great enablers for IoT. Prospering from the Internet of computers to the remote and somewhat fuzzy goal of an Internet of Things is something that must therefore be done one step at a time. Nevertheless, there are still some current challenges limiting the adoption of IoT, such as (Mattern and Floerkemeier 2010; Zeinab and Elmustafa 2017):

- Scalability: The concept of an Internet of Things is broader than that of the conventional Internet of computers, because things cooperate within an open environment. Basic functionality such as communication and service discovery therefore need to function equally efficiently in both small-scale and large-scale environments. IoT requires new functions and methods in order to ensure efficient operation for scalability. 
ToSEE - Tourism in Southern and Eastern Europe, Vol. 5, pp. 163-175, 2019

T. Car, Lj. Pilepić Stifanich, M. Šimunić: INTERNET OF THINGS (IOT) IN TOURISM AND ...

- Self-Organizing: Smart things should not be managed as computers that require their users to configure and adapt them to particular situations. Mobile things, which are often only sporadically used, need to establish connections spontaneously, and be able to organize and configure themselves to suit their particular environment.

- Data volumes: Some IoT application scenarios will involve infrequent communication, and by gathering information from sensor networks or from logistics and large-scale networks, huge volumes of data will be collected on central network nodes or servers. The term representing this phenomenon is 'big data', which requires many operational mechanisms in addition to new technologies for storing, processing and management.

- Data interpretation: To support the users of smart things, there is a need to interpret the local context determined by sensors as accurately as possible. For service providers to profit from the disparate data that will be generated, they need to be able to draw some generalizable conclusions from the interpreted sensor data.

- Interoperability: Each type of smart object in IoT has different information, processing and communication capabilities. Different smart objects would also be subjected to different conditions such as energy availability and communications bandwidth requirements. To facilitate the communication and cooperation of these objects, common standards are required.

- Automatic Discovery: In dynamic environments, suitable services for things must be automatically identified, which requires appropriate semantic means of describing their functionality.

- Software complexity: A more extensive software infrastructure will be needed on the network and on background servers in order to manage the smart objects and provide services to support them. That is because the software systems in smart objects will have to function with minimal resources, as in conventional embedded systems.

- Security and privacy: In addition to the security and protection aspects of the Internet such as communications confidentiality, the authenticity and trustworthiness of communication partners, and message integrity, other requirements would also be important in an Internet of Things. There is a need to access certain services or prevent communications with other things in IoT, and business transactions involving smart objects would need to be protected from competitors' prying eyes.

- Fault tolerance: Some objects in IoT are much more dynamic and mobile than Internet computers, and they are changing rapidly in unexpected ways. Structuring an Internet of Things in a robust and trustworthy manner would require redundancy on several levels and an ability to automatically adapt to changed conditions.

- Power supply: Things typically move around and are not connected to a power supply, so their smartness needs to be powered from a self-sufficient energy source. Although passive RFID transponders do not need their own energy source, their functionality and communications range are very limited. Energy saving is a factor not only in hardware and system architecture, but also in software, for example, the implementation of protocol stacks, where every single transmission byte will have to justify its existence. 
ToSEE - Tourism in Southern and Eastern Europe, Vol. 5, pp. 163-175, 2019

T. Car, Lj. Pilepić Stifanich, M. Šimunić: INTERNET OF THINGS (IOT) IN TOURISM AND ...

- Wireless communications: From an energy point of view, established wireless technologies such as GSM, UMTS, Wi-Fi and Bluetooth are far less suitable; more recent WPAN standards such as ZigBee and others still under development may have a narrower bandwidth, but they do use significantly less power.

- Interaction and short-range communications: Wireless communication over distances of a few centimetres will suffice, for example, if an object is touched by another object or a user holds their mobile against it. Where such short distances are involved, very little power is required, addressing is simplified (as there is often only one possible destination) and there is typically no risk of being overheard by others.

\section{CONCLUSION}

This paper seeks to provide insight into the concept of the Internet of Things and its application as one of the fast growing technologies that are expected to be used in the future. A wide range of IoT applications have been adopted in the last few years. The Internet of Things is becoming a standard in the hospitality business. From enabling automatic check-ins and check-outs to hotel rooms and helping guests locate their travel destination to monitoring the health status of people, IoT will make things easier. In addition, IoT is a must, since it offers many advantages, such as cost reduction, increased productivity, greater efficiency of operations, more-satisfied customers/guests and differentiated services.

The findings show that IoT in tourism and hospitality has huge potential. Because the Internet of Things allows many devices to be connected at the same time, it provides numerous opportunities in tourism as well as in the hospitality industry. The most relevant application fields in tourism and hospitality have been presented. However, it is also necessary to highlight certain obstacles and challenges in the process of implementing IoT such as security, "high" investment cost, technology infrastructure, communications infrastructure and IoT standards.

In order to prepare for what is coming, hotel managers and employees in tourism should be ready to adopt new technologies (such as IoT) to improve the efficiency and effectiveness of various work processes. We believe that this paper will be useful to researchers and practitioners in the field, helping them to understand the huge potential of IoT, especially in tourism and hospitality.

\section{REFERENCES}

Ansari, F. (2018), Internet of Things in Hotel Industry, Available at: https://qloapps.com/internet-things-hotelindustry/ (accessed 16/01/2019)

Atzori, L., Iera, A. \& Morabito, G. (2010), "The internet of things: A survey", Computer networks, Vol. 54, No. 15 , pp. $2787-2805$.

Devotex (n.d.), Internet of Things in Hospitality: Smart Hotels, Available at: http://www.devotex.net/blog/iot/internet-of-things-in-hospitality-smart-hotels/ (accessed 14/01/2019)

Dlodlo, N., Gcaba, O. \& Smith, A. (2016, May), "Internet of things technologies in smart cities", in 2016 ISTAfrica Week Conference, IEEE, pp. 1-7. 
ToSEE - Tourism in Southern and Eastern Europe, Vol. 5, pp. 163-175, 2019

T. Car, Lj. Pilepić Stifanich, M. Šimunić: INTERNET OF THINGS (IOT) IN TOURISM AND ...

eMarketer (2016), How the Internet of Things Is Transforming Travel, Available at: https://www.emarketer.com/article.aspx?R=1013487\&RewroteTitle=1 (accessed 13/12/2018)

Gartner n.d., IT Glossary - Internet of Things, Available at: https://www.gartner.com/it-glossary/internet-ofthings/ (accessed 15/01/2019)

Gubbi, J., Buyya, R., Marusic, S. \& Palaniswami, M. (2013), "Internet of Things (IoT): A vision, architectural elements, and future directions", Future generation computer systems, Vol. 29, No. 7, pp. 16451660. http://dx.doi.org/10.1016/j.future.2013.01.010

IERC n.d., Internet of Things, Available at: http://www.internet-of-things-research.eu/about_iot.htm (accessed 22/01/2019)

ITU (2015), Internet of Things Global Standards Initiative, Available at: https://www.itu.int/en/ITU-T/gsi/iot/Pages/default.aspx (accessed 17/01/2019)

Jaakkola, E. (2018), Five IoT Solutions That Can Improve Your Guest Experience Radically, Available at: https://www.hotelspeak.com/2018/09/five-iot-solutions-that-can-improve-your-guest-experienceradically/ (accessed 15/01/2019)

Kansakar, P., Munir, A. \& Shabani, N. (2017), "Technology in hospitality industry: Prospects and challenges", arXiv preprint arXiv:1709.00105.

Kaur, K. \& Kaur, R. (2016), "Internet of things to promote tourism: An insight into smart tourism", International Journal of Recent Trends in Engineering \& Research, Vol. 2, No. 4, pp. 357-361.

Kranenburg, R.V. (2008), The Internet of Things: A critique of ambient technology and the all-seeing network of RFID, Insitute of Network Cultures, Amsterdam.

M. Pustišek, Mali, L. \& Kos, A. (2014), "Scopes in Internet of Things for Active Tourism and Leisure", ERK'2014, Portorož, pp. 85-88. http://erk.fe.uni-lj.si/2014/pustisek(scopes)p.pdf

Mattern, F. \& Floerkemeier, C. (2010), "From the Internet of Computers to the Internet of Things". In From active data management to event-based systems and more, Springer, Berlin, Heidelberg, pp. 242259.

Mimos, Berhad (2014), IoT Idea Book, Kuala Lumpur, Malaysia, Available at: http://www.mimos.my/wpcontent/uploads/2016/01/IoT-Idea-Book-Experiential-Travel-and-Tourism.pdf (accessed 16/01/2019)

Mingjun, W., Zhen, Y., Wei, Z., Xishang, D., Xiaofei, Y., Chenggang, S. \& Jinghai, H. (2012, October), "A research on experimental system for Internet of things major and application project", in $20123 \mathrm{rd}$ International Conference on System Science, Engineering Design and Manufacturing Informatization, IEEE, Vol. 1, pp. 261-263.

Miorandi, D., Sicari, S., De Pellegrini, F. \& Chlamtac, I. (2012), "Internet of things: Vision, applications and research challenges", Ad hoc networks, Vol. 10, No. 7, pp. 1497-1516. http://dx.doi.org/10.1016/j.adhoc.2012.02.016

Nidhi, D. (2018), 8 Ways in Which IoT is Shaping the Future of Travel Industry, Available a https://www.digitaldoughnut.com/articles/2018/january/ways-in-which-iot-is-shaping-the-futureof-travel (accessed 13/01/2019)

Ray, P.P. (2018), "A survey on Internet of Things architectures", Journal of King Saud University-Computer and Information Sciences, Vol. 30, No. 3, pp. 291-319.

Revfine n.d., How the Internet of Things (IoT) can Benefit the Hospitality Industry. Available at: https://www.revfine.com/internet-of-things-hospitality-industry/ (accessed 12/01/2019)

Revfine n.d., How the Internet of Things (IoT) can Benefit the Travel Industry. Available at: https://www.revfine.com/internet-of-things-travel-industry/ (accessed 12/01/2019)

Saranya, C.M. \& Nitha, K.P. (2015), "Analysis of Security methods in Internet of Things", International Journal on Recent and Innovation Trends in Computing and Communication, Vol. 3, No. 4, pp. 1970-1974.

Sethi, P. \& Sarangi, S.R. (2017), "Internet of things: architectures, protocols, and applications", Journal of Electrical and Computer Engineering, Vol. 2017, pp. 1-25. https://doi.org/10.1155/2017/9324035

Skelia (2018), How Iot Is Changing The Travel Industry Today And Tomorrow, Available at: https://skelia.com/articles/how-iot-is-changing-the-travel-industry-today-and-tomorrow/ (accessed $14 / 01 / 2019)$

Skift (2016), How the Internet of Things Will Impact Travel in 2017 and Beyond, Available at: https://skift.com/2016/12/19/how-the-internet-of-things-will-impact-travel-in-2017-and-beyond/ (accessed 13/01/2019)

Statista (2019), Size of the IoT market worldwide from 2016 to 2020 (in billion U.S. dollars), Available at: https://www.statista.com/statistics/764051/iot-market-size-worldwide/ (accessed 15/01/2019)

Sterling, G. (2016), Report: Nearly 90 percent of airports deploying proximity sensors, beacons, Available at: https://marketingland.com/report-nearly-90-percent-airports-deploying-proximity-sensorsbeacons-197511 (accessed 14/01/2019) 
ToSEE - Tourism in Southern and Eastern Europe, Vol. 5, pp. 163-175, 2019

T. Car, Lj. Pilepić Stifanich, M. Šimunić: INTERNET OF THINGS (IOT) IN TOURISM AND ...

Techtarget n.d., Internet of Things, Available at:

https://internetofthingsagenda.techtarget.com/definition/Internet-of-Things-IoT (accessed 19/01/2019)

Tossel, D. (2015), How 26 Billion "Internet of Things" Devices Will Impact The Hotel Industry, Available at: https://www.hotelexecutive.com/business_review/4299/how-26-billion-internet-of-things-deviceswill-impact-the-hotel-industry (accessed 21/11/2018)

Wu, X. (2017), "Smart tourism based on internet of Things", Revista de la Facultad de Ingenieria, Vol. 32, No. 10, pp. 66-170.

Zeinab, K.A.M. \& Elmustafa, S.A.A. (2017), "Internet of Things applications challenges and related future technologies”, World Scientific News, Vol. 2, No. 67, pp. 126-148.

Tomislav Car, PhD, Postdoctoral Research Assistant University of Rijeka

Faculty of Tourism and Hospitality Management

Primorska 42, P.O.Box 97, 51410 Opatija, Croatia

Phone: +385 (0)51294 180

E-mail: tcar@fthm.hr

Ljubica Pilepić Stifanich, PhD, Associate Professor University of Rijeka

Faculty of Tourism and Hospitality Management Primorska 42, P.O.Box 97, 51410 Opatija, Croatia Phone: +385 (0)51 294180

E-mail: ljubicap@fthm.hr

Mislav Šimunić, PhD, Full Professor

University of Rijeka

Faculty of Tourism and Hospitality Management

Primorska 42, P.O.Box 97, 51410 Opatija, Croatia

Phone: +385 (0)51 294180

E-mail: mislavs@fthm.hr 